How to cite this paper:

Zakaria, N. H., Ahmad, M. N., Mohd Noor, M. S. A., \& Ahmad, M. (2018). Knowledge integration among flood disaster management team: Lessons from the Kemaman district. Journal of Information and Communication Technology, 17 (3), 393-408.

\title{
KNOWLEDGE INTEGRATION AMONG FLOOD DISASTER MANAGEMENT TEAM: LESSONS FROM THE KEMAMAN DISTRICT
}

\author{
${ }^{1}$ Nor Hidayati Zakaria, ${ }^{2}$ Mohammad Nazir Ahmad, \\ ${ }^{3}$ Mohd Saiful Anuar Mohd Noor $\&{ }^{4}$ Mazida Ahmad \\ ${ }^{1}$ Faculty of Computing, Universiti Teknologi Malaysia, Malaysia \\ ${ }^{2}$ Institute of Visual Informatics, Universiti Kebangsaan Malaysia, Malaysia \\ ${ }^{3}$ Kemaman District Office, Terengganu, Malaysia \\ ${ }^{4}$ School of Computing, Universiti Utara Malaysia, Malaysia
}

hidayati@utm.my;mnazir@ukm.edu.my; saifulm.noor@gmail.com; mazida@uum.edu.my

\begin{abstract}
Although flooding is a common disaster event in Malaysia, issues such as information and knowledge integration still have yet to be resolved. Flood management operations seem to be handled in an ad-hoc manner comprising issues such as miscommunication, lack of common understanding during coordination practices, and lack of smooth mutual agreement among flood management agencies. Thus, this paper discusses the flood knowledge integration measures that have been applied by the flood management team for Kemaman District, Terengganu, the first district achieved a Gold Standard award for flood disaster management in Malaysia. This study comprises a qualitative research method using a variety of techniques. These include a case study approach performed by interviewing key informants as well as studying archival documents. In addition, site visits were made to flood location areas in order to better understand the district's flood management team's achievement. The result
\end{abstract}


of knowledge integration practice in preliminary, actual and post-flood phases is discussed in this research. This study shows the importance of knowledge integration as a successful factor for the district's flood management plan.

Keywords: Flood disaster, flood management, knowledge integration.

\section{INTRODUCTION}

Malaysia is fortunate to be free from severe natural disasters such as earthquakes, volcanic eruptions and typhoons. However, with heavy rainfall carried by two monsoon winds blowing from the south-west and northeast annually, flood disasters have become a serious issue in the country as the number of occurrences has increased each year, resulting in significant damage and losses. Persistent flooding has always been associated with the East Coast states of Malaysia, especially Terengganu and Kelantan. In 2013, the Kemaman district in Terengganu was one of the worst-hit areas. This numbered prominently among major disasters recorded in Terengganu since 1971. More than 20,000 people were evacuated to relief centres where all roads were closed and communication with outsiders was not possible. The unexpected situation resulted in the district virtually becoming an island after being cut off in all directions ("Flood Situation Worsens", 2013). As a consequence, the immense flood literally paralysed Kemaman as power lines had to be disconnected for safety ("Kemaman Suffers Worst Flood", 2013) with resultant shortages of food and basic necessities.

Following lessons learnt from the incident which caused utter chaos in 2013, the Kemaman District Office subsequently initiated a sort of systematic plan to prevent the situation from re-occurring. Since April 2014, a flood disaster committee has been formed and 69 relief centres identified. Preparation of an operation has been set up by district authorities to be used in preliminary, actual and post-flood events with special emphasis placed on the worst case scenarios. This then resulted in the district being awarded with a gold standard of flood management team award in 2014. In December of that year, the Prime Minister announced that the Kemaman District's flood management plan would become the model for the Standard Operating Procedure (SOP) in relation to flood management in flood-hit areas. Accordingly, in May 2016, the Kemaman District flood management system won a prize at the World Summit held at the Information Society Forum in Geneva ("Kemaman Wins Award in Geneva", 2016). The system was deployed and launched in Kemaman as it was one of the worst-hit districts during the 2013 flood. Learning from past 
mistakes, it is envisaged that the system can now be used in other flood-prone states during the year-end monsoon season.

In response to the above scenarios, this paper aims to understand and examine the special and unique factors of the Kemaman District's flood management plan that earned it the Gold Standard benchmark for Malaysia. Does it relate highly to the integration of knowledge via close communication among flood management teams? To achieve this intention, we concentrated our study on the flood knowledge integration perspective by proposing that knowledge integration be strengthened for flood disaster management as a potential solution.

\section{THE RESEARCH BACKGROUND}

The principle of flood disaster management highlights the qualities of accuracy and speed that are required for compilation of information for decision-making and forecasting purposes. From the disaster management point of view, knowledge management (KM) is perceived as an important element for the procurement of disaster-related data (Seneviratne et al., 2010). Flood management procedures in Malaysia are confronted with numerous challenges. Multiple organizations were engaged in the disaster management field without any having proper documentation on how to determine the respective roles of cross-agencies and authorities. Up until now, it has been unclear how the knowledge of agencies and authorities is shared and integrated between each other. The existing practice of flood management in Malaysia is generally weak in terms of information-sharing and lack of coordination between agencies (Mohd Rodzi, Zakaria \& Ahmad, 2016). Certain challenges in the current practice of flood management in Malaysia are also highlighted by Othman et al. (2013) who discovered issues of weak coordination among flood management agencies with no valid documentation to dictate crossagency roles. In addition, knowledge related to flood management is available in large amounts from various agencies in Malaysia but is not well-managed. Accordingly, this gives rise to higher casualties during flood relief operations.

Realizing a critical need to manage knowledge and past experiences so as to ensure significant improvement in flood management practices, this research proposes a process of knowledge integration (KI) for managing floods in Malaysia. In this process, the KI is identified as an important aspect for a flood management practice. Furthermore, it is envisaged that KI could eventually serve as a platform by which to unite fragmented and scattered pieces of knowledge among agencies. Although KI has existed within the knowledge 
framework of many domains and has significantly contributed to the effectiveness of the decision support system and forecasting (Heisig, 2009), no studies have explicitly mentioned and studied this in the flood management context. In fact, KI has been implemented differently in various domains due to inconsistent understanding of the current implicit nature of KI.

\section{FLOOD LITERATURE}

In recent years, the world has witnessed the devastating impact of natural disasters that negatively affect human life and urban development. With an alarming rate in the increase of such occurrences worldwide, it calls upon the need for researchers to identify, analyze and find a solution to curb this problem. Therefore, in the past decades, many literature works concerning disasters (especially floods) have been studied and published from various perspectives. Although there are differences in approaches taken by various researchers, it is observed that most researchers agree that managing floodrelated knowledge takes the highest priority in finding a potential solution for flood scenarios as they are dynamic in nature. Among the approaches taken is the utilization of $\mathrm{KI}$ in relation to flood-related matters.

In most cases, the four main phases in flood events are known as mitigation, preparedness, response and recovery. In this paper, all four phases are categorized into preliminary (mitigation, preparedness), actual (response) and post (recovery) flood management procedures respectively.

\section{Flood Management in Malaysia}

The geographical location of Malaysia seems to render the country substantially prone to natural disasters which have occurred quite frequently over the last few years. Each year, floods have forced thousands of people to evacuate their homes in several states of Peninsular Malaysia, particularly in Terengganu and Kelantan.

Although Kemaman still faces the prospect of flood events each year with people suffering damage (see Figure 1), the flood evacuation work in the district has been carried out smoothly. The assistance was delivered in a timely fashion and the victims felt comfortable at relief centres, as reported by the Terengganu State Secretary in December 2016 ("Terengganu Takes Measures to Alleviate Flooding", 2016). This is primarily due to the initiatives that had been taken by the Kemaman District Office, which conducts progressive measurements to attempt to alleviate flooding since the flood incidents in 2013. 


\section{FLOOD DISASTER}

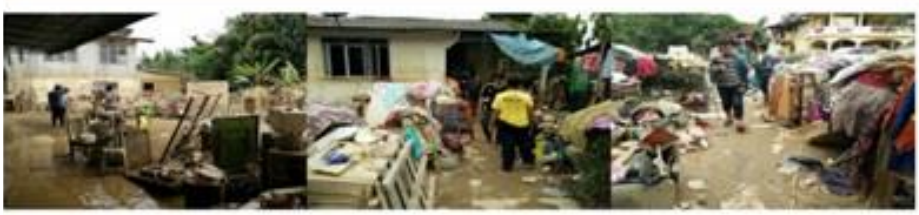

\section{DAMAGE DUE TO FLOODS}
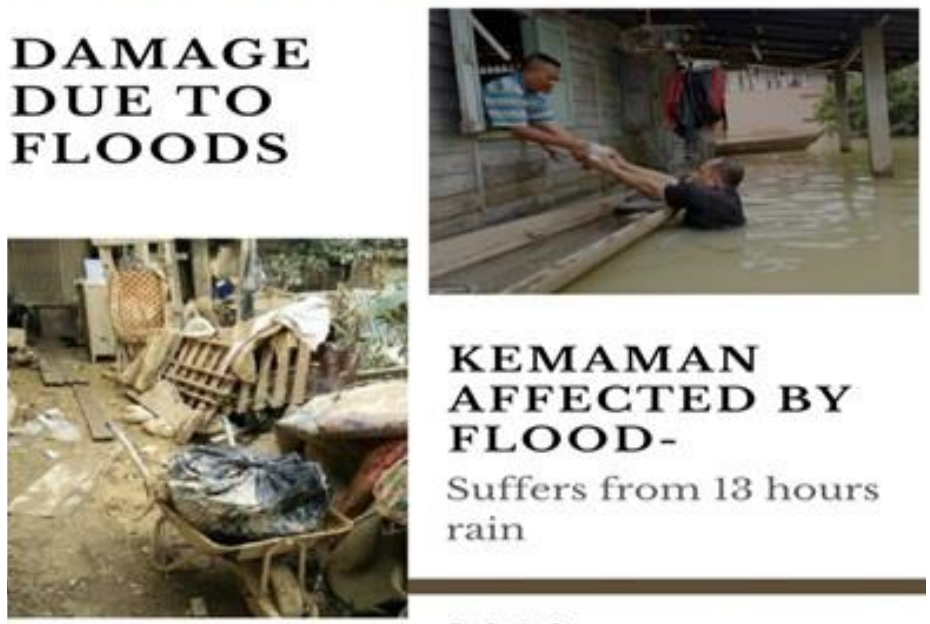

KEMAMAN AFFECTED BY FLOOD -

Suffers from 13 hours rain

2016

Figure 1. Flood Disaster in Kemaman District, 2016.

Basically, there are many agencies involved in disaster relief operations and coordinating these agencies is quite challenging since it involves tasks that require speed and accuracy in a very critical environment. Generally, flood relief operations in Malaysia are coordinated by the National Security Council (MKN). The major issues faced by MKN are poor coordination and lack of communication by which to effectively execute disaster relief operations. With limited resources and manpower, disaster relief operations need to be conducted in the most efficient manner possible in order to avoid wastage and be able to deploy rescue teams to save as many lives as possible in the most critical scenario. Although each of the agencies has its own website and portal, it is on a stand-alone basis and knowledge is not shared with other agencies. This creates some problems, such as: information differing despite reporting the same thing; lack of clarity and low amount of access by the targeted audience due to trust issues. 


\section{Knowledge Integration}

In general, $\mathrm{KI}$ is referred to as a process by which to add new knowledge into existing knowledge. However, the main concern is, namely: what does it mean to integrate knowledge and what are the common reasons for KI to happen and be practiced? Grant (1996) viewed KI within an organisation as a process of integrating the knowledge of experts among employees. Grant argues that most instances of KI happen in a tacit form (where it is more exclusive and valuable) rather than in an explicit form, as this involves personal competency, skills and experience. From a different point of view, Enberg et al. (2006) explored the dynamism of KI from the perspective of acting and interacting within a team. Their approach emphasized the importance of the project management function in assuring KI by appreciating the learning dynamic with reference to the project context. This research discovered that $\mathrm{KI}$ is a process of combination which can produce a new form of knowledge (Mohd Rodzi et al., 2014), where KI transfers knowledge, both tacit and explicit, across organizational boundaries and shares it with individuals and teams. In addition, it includes the process of recognizing the knowledge in comparative fields and incorporating existing knowledge so as to create new knowledge. It involves the process of identifying knowledge of similar fields and then integrating that knowledge to create a new form of knowledge that is able to deliver the expectation as solutions to problems or complexity of tasks. Thus, a solution can be conveyed to solve problems and may result in a reduction of complexity of tasks. Hence, we argue that integrated knowledge has high potential as a possible solution to any problems confronted by flood management teams in Malaysia.

\section{THE RESEARCH METHODOLOGY}

This study comprises a qualitative research method which includes a case study approach by interviewing key informants from the Kemaman District Office, representatives of the Committee of Community Development (JKKK) as well as Smart Community team members through open-ended interviews as our respondents.

In addition, we applied a few other qualitative techniques involving: the study of archival documents; gathering of observations through digital photographs; and finally, attending site visits to three flood locations (analyzing flood sensors and flood telecommunication equipment at Kampung Air Puteh, relief centres and food depots). During these visits, we made observations and recorded them through filing of notes and digital photographs. Archival documents 
related to meeting agendas, planning of activities, procedures and letters provided further data. We supplemented brief handwritten notes during the observation sessions to retain data not captured on the camera. The notes were used to assist us in determining what the observed items mean and provide us with answers to our research questions. Some of the findings from interviews were used in verifying our observational data. For example, images from a camera could not capture the information that we needed. Thus, we utilized results from interview sessions to complete the final view of the research. These methods drove us to analyze actual situations and initiatives that have been undertaken. These were focused on highly in relation to the existence of KI points of view. Figure 2 shows our site visit activities during the data collection process with assistance from the Kemaman District Office staff.

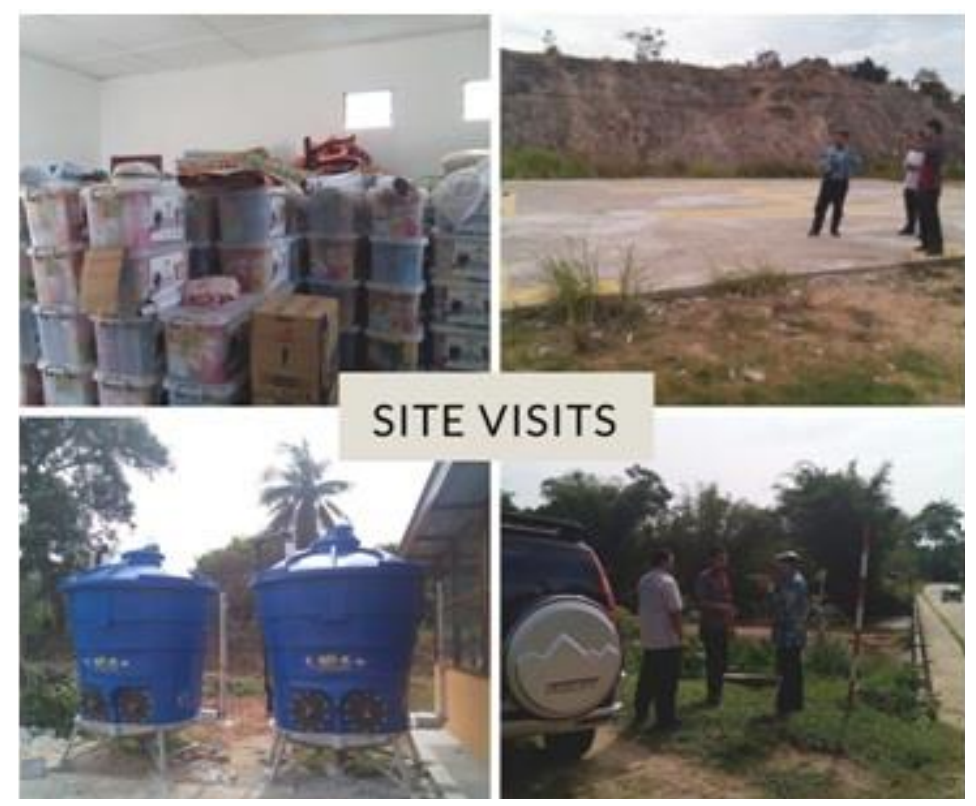

Figure 2. Site Visits.

\section{RESULTS AND DISCUSSION}

\section{Integration of Knowledge in Preliminary Flood Phase}

In the preliminary flood phase, various flood awareness programs can be conducted by local and national authorities, including: the district authorities; 
National Security Council (MKN); youth clubs; medical teams and logistics support organizations. The activities cover basic information on different ways to handle floods, flood kits for victims and information on relief centres. Placement centres, cooking areas, food depots and places to store items donated by the public have also been identified during this period. The level of readiness among the secretariat is being tested through the flood simulation process, which includes: receipts for essential items; registration of victims with the allocated relief centres; food management; and distribution of goods to be donated to flood victims.

All required equipment items were identified and tested to smooth disaster management operations before the onset of the flood season. Those equipment items included generator sets and logistic equipment items such as boats, walkie-talkies and the portable mobile cellular site that provides temporary network and wireless coverage in locations where cellular coverage is minimal or compromised. The District authority is working closely with telecommunications companies like Celcom Axiata Bhd, Maxis Bhd, DiGi. Com Bhd and Telekom Malaysia Bhd, to ensure that the communications system remains effective during flood events. This telecommunication technology has been taken advantage of by the Kemaman District's flood management teams to promote $\mathrm{KI}$ among them.

The required and up-to-date knowledge is intended to be well-shared and integrated among the affected victims and relevant agencies through WhatsApp and Telegram social media application software forums. Social media tools have been widely-used among committees to bond with other people in order to access and receive knowledge, as well as reply to and discuss important posts and messages among each other. The utilization of the social media tools has facilitated flood-related knowledge to be exchanged and integrated in a speedier and more effective way.

The East Coast district in Terengganu now has three helipads complete with global positioning system (GPS) coordinates that will help cut the time required to send food and other essential assistance to the victims, located at Batu 14 in Kuala Tayor, Felda Seberang Tayor and Pasir Gajah. Hospitals were also listing vulnerable patients including expectant mothers who were due to give birth during the flood season for contingency plans (Hamdan, 2015). Each flood relief centre is equipped with temporary clinics to check on the health condition of flood victims (Abdullah, 2014). Since every single thing related to flood management was well-planned during the pre-flood phase, it is no wonder that the Kemaman District's flood management plan turned into a success story in Malaysia. 


\section{Integration of Knowledge in Actual Flood Phase}

Over the duration of the floods, once the first relief centre was opened for the victims, the main operations room was activated. All relevant agencies were then instructed to open their own operations rooms. Meetings on the coordination of the various operations among all related authorities and agencies were held daily at $8.00 \mathrm{pm}$ at the main operations room to report on and synchronize plans and critical activities that needed to be taken on the following day. The close monitoring and interactive communication among the flood management team, together with the utilization of the latest communication technology has been identified as a factor that triggered a successful KI among the members.

Seven day supplies of food were also despatched to each relief centre and food depot, as an improvement upon the previously-used three day food supplies of the existing standard operating procedure of MKN. Steps were taken to ensure that the relief centres were equipped with necessary equipment for victims including blankets, mats, sleeping bags, gas cylinders and power banks. However, among all of those stated activities, efforts to rescue flood victims were still given top priority.

During the actual flood phase, the use of social media was extremely helpful for crisis administration by means of sharing and integrating knowledge among committees and the community, in particular during the response period. The Whatsapp and Telegram social media platforms rapidly turned into a powerful method for quick knowledge exchange in the flood response compared to fax, email and other types of communication. In fact, it really provided access to quick feedback and immediate information from the committee and community at the flood scenes.

\section{Integration of Knowledge in Post-Flood Phase}

After the floodwaters receded, damage to public property such as bridges, buildings and roads, as well as private property (houses and cars) was assessed. The various district offices were given the task of centralising and managing all the contributions and donated items, including daily essentials.

One week after the last relief centre was closed, a review of the flood management operations was carried out and proposals were presented to bring about further improvements. As a result of the knowledge integration plan among authorities and agencies, the entirety of authorities in Malaysia concluded that the floods that hit the Kemaman district in 2014 came within control; an absolutely far better result than that of 2013. 


\section{Integrated Flood Knowledge Management Activities}

Flood knowledge was integrated into teams with a diversity of authorities, agencies, background and disciplines. The main integration management team consists of authorities and agencies as illustrated in Figure 3. The details in Figure 3 further exemplify necessary flood knowledge that was shared and integrated among authorities and agencies of Kemaman's flood management team. The integration of flood knowledge has helped to improve flood disaster management strategies and enabled them to better adapt.

\section{FLOOD KNOWLEDGE INTEGRATION}

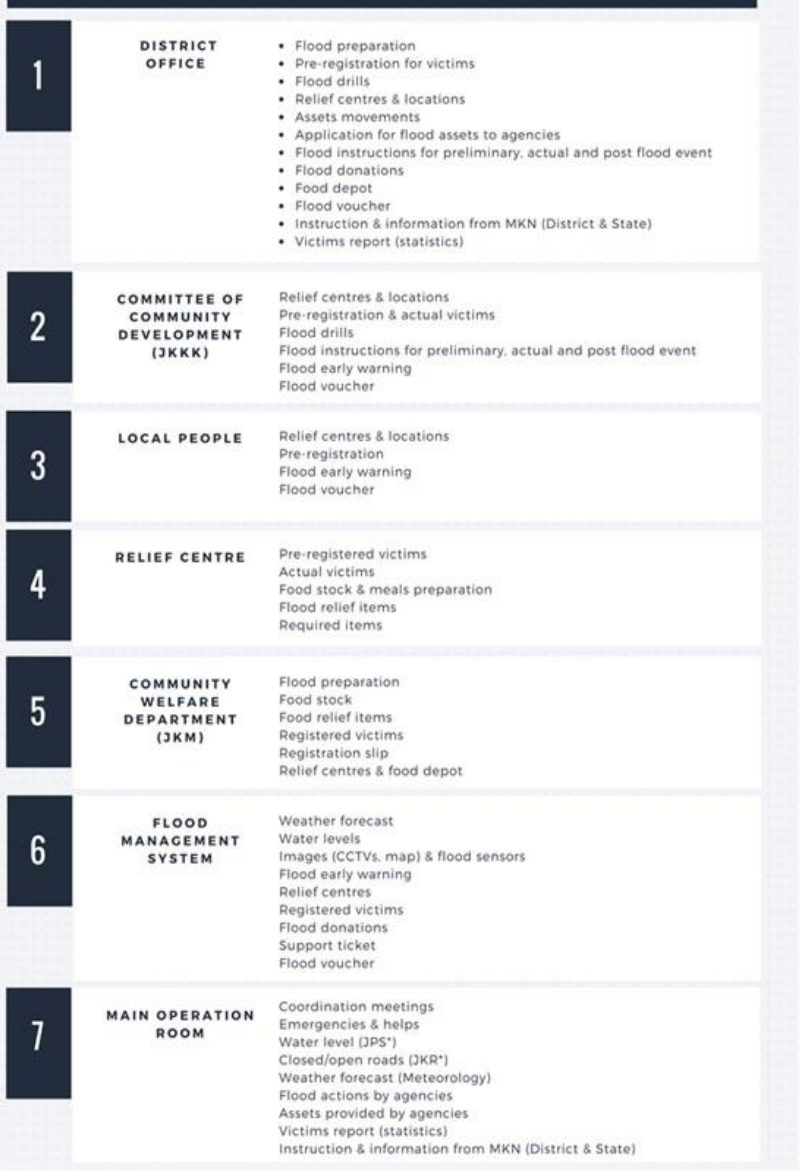

Figure 3. Flood Knowledge Integration among Flood Management Team. 
In order to have better KI, authorities and agencies need to realize and define their different roles and responsibilities. Recognizing each function with sufficient communication helps to combine knowledge for improving flood management within a team. For example, there should be input from both humans and technology, such as the Committee of Community Development (JKKK) and Flood Management System (FMS). This would reduce the vulnerability of victims by improving preparedness and early warning systems, thereby enabling them to better adapt and respond.

The emergence of new innovations in the social media network with communication instruments can help to ease numerous processes in the wide distribution of knowledge. The most popular social networking sites, such as WhatsApp and Telegram, have been used as part of the communication tools for the Kemaman District's flood management team. This integration of knowledge was provided by different actors who helped to develop successful strategies to mitigate the impact of flooding in the district. Figure 4 shows the knowledge interaction among the Kemaman District flood management team.

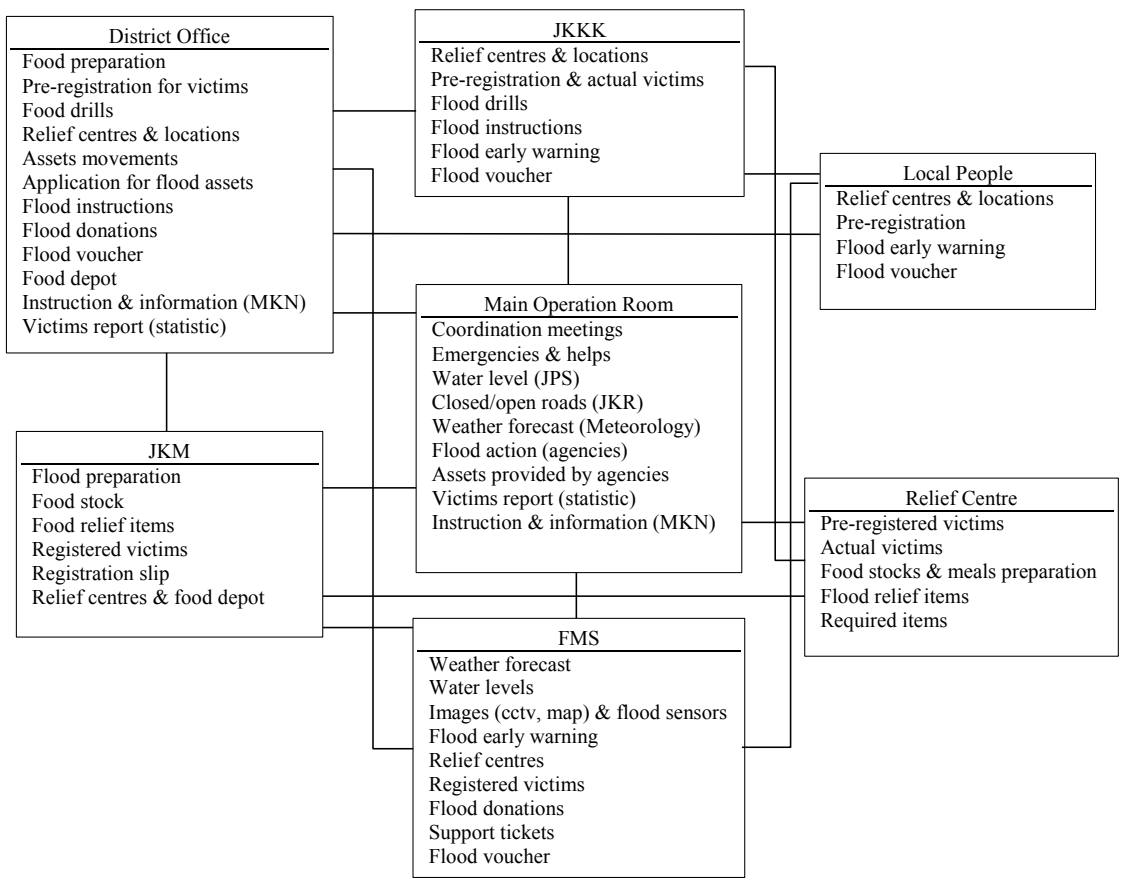

Figure 4. Knowledge Interaction among Flood Management Team. 
The interaction of flood knowledge, as demonstrated in Figure 4, occurs during the preliminary, actual and post-flood event phases. During these phases, all the team members have a high level of communication to ensure there are no miscommunications or misleading knowledge put about by the use of just any kind of technologies. The main operations room plays a crucial role in coordinating all the agencies in the team.

\section{Develop strong teamwork}

In an effort to provide vulnerable victims with support and strategies to cope with a flood disaster, a group of representatives from among local people has formed an organization known as the Committee Community Development (JKKK). This organization has been working together with the Kemaman District authorities and government agencies such as National Security Council (MKN), Community Welfare Department (JKM), Fire and Rescue Department (JPBM), Royal Malaysia Police (PDRM) and others. This strong team was built after the 2013 flood tragedy in the district; in response to suggestions, they decided to allocate their resources as close as possible to the point of delivery services. Each authority and agency in the team shared the same interests, vision and objectives. This is achieved by integrating their knowledge in improving the procedures and plan for future flood management. Adequate and sufficient arrangements for accountability have been organized for every authority and agency. The newly-created team is held accountable for a rapid response to any relevant necessary actions and tasks which need to be undertaken. By having frequent face-to-face meetings, this team was able to avoid misleading information.

Interestingly, there is proactive involvement by the participation of representatives of local people in the team. The Kemaman District Office has initiated small functional groups (known as JKKK) as one of its most effective ways to strengthen flood preparedness at the community level. Each group represents a specific village or catchment area in the Kemaman district. This community involvement is significant in that it provides a bridge of knowledge from local people to authorities and agencies to attend to incident reports in the community. Strong community engagement is required in order to produce long-term success of flood disaster management. Results have shown that this is the best way to enable communities to become more participative, cooperative and organized by linking them with the official flood disaster agencies.

\section{Reform normal Standard Operating Procedure (SOP)}

Subsequent to a very anxious time during the flood incident in 2013, the Kemaman District Office took the initiative of expediting certain procedures in their flood management plan. They achieved this by re-structuring the normal process of registration as stated in the Standard Operating Procedure 
(SOP) provided by the Department of Community Welfare or Jabatan Kebajikan Masyarakat (JKM) and the National Security Council (MKN).

The District Office opened for a pre-registration process for potential flood victims by involving the Committee of Community Development (JKKK) in the pre-flood phase. This pre-registration process was done through the filling out of registration forms facilitated by JKKK. These were then forwarded to the District Office to be confirmed and keyed-in into the Flood Management System (FMS). The pre-registration data will be used during flood and postflood phases by the District Office, relief centres, JKM, JKKK in addition to the main operations room to validate the actual victims for flood support and organize voucher distribution. Surprisingly, this initiative had shortened the flood time management from being a one (1) year process of completion time to only three (3) months. Hence, this saved about nine (9) months' worth of management process time.

Further, an improvement was taken to ensure flood victims were given full and continuous meal support by supplying a seven day food supply ahead at nominated food depots. This procedure showed an improvement of four days upon the three day food supplies of existing standard operating procedure that was stated by the National Security Council (MKN) and the Community Welfare Department (JKM).

\section{The Flood Management System}

Technical information alone, without having consideration for both technical information and local wisdom, can result in the ultimate failure of a system that is being developed. In Kemaman, the Flood Management System (FMS) was developed by the Smart Community Team for managing flood data of the district. This enables the system to produce early flood warnings, flood forecasting, flood risks in catchment areas, flood reports and other necessary actions. This initiative is very useful for both contingency planning and taking immediate actions when responding to a flood emergency. When the river's water level reaches a certain point, a flood warning will be broadcast by the system to all registered local people in affected communities and their JKKK. Two modules were involved in this situation, namely, Floodforecasting and My Alert. The My Alert module also distributed information of the evacuation centres for the specific catchment area. In some cases, local people might not understand the distributed flood alert information. Thus, explanation and instructions from JKKK helped and facilitated the community in terms of taking decisions on matters of evacuation and preventive actions, as well as intensifying efforts to assist flood victims, especially those living in areas badly affected by the floods. 


\section{CONCLUSION}

This research presents an insightful discussion on the KI aspects of flood disaster management encompassing three main phases, namely: preliminary (mitigation and preparedness); actual (response); and post-flood (recovery). The integration of flood knowledge among flood management teams in Kemaman has also been discussed in order to demonstrate how the KI helped to achieve a successful outcome of the District's flood management plan. The Kemaman District's flood management plan has achieved a Gold Standard benchmark as compared with other flood management teams in Malaysia. As discussed in the early sections of this paper, KI has been found to be a factor contributing to the success of the District's flood management team with facilitation by technologies such as FMS, social media applications of WhatsApp and Telegram, as well as GPS and flood sensors. Indeed, leadership seems to play an important role in the whole situation. However, future improvement still needs to be considered. Current lessons learned from the Kemaman District's flood management team trigger the need for a few aspects to be enhanced so as to provide a better flood management plan. First, we see that the risk management aspect for the affected community is still limited. Second, a flood prediction data model from rainfall also needs to be included in the FMS, to assist in the existing flood forecasting module by the river's water level measurement. Lastly, the measurement of the river's water level in the FMS needs to be improvised so as to provide an accurate result for flood prediction catchment areas, and to advise the local people to be prepared to face the possibility of floods as forecast by the system.

\section{ACKNOWLEDGMENT}

The authors wish to thank the Malaysia Ministry of Higher Education for funding this study under the Long Term Research Grant Scheme (LRGS/bu/2012-UUM/Teknologi Komunikasi dan Informasi).

\section{REFERENCES}

Abdullah, Z. (2014, November 20). Clinics at all Terengganu flood relief centres. New Straits Times. Retrieved from http://www.nst.com.my/ node $/ 54798$ 
Enberg, C., Lindkvist, L. \& Tell, F. (2006). Exploring the dynamics of knowledge integration acting and interacting in project teams. Management Learning, 37(2), pp. 143-165.

Grant, R. M. (1996). Toward a knowledge based theory of the firm. Strategic Management Journal, 17 (Winter Special Issue) 109-122.

Hamdan, N. (2015, November 25). Kemaman prepared to face flood season. The Star. Retrieved from http:/www.thestar.com.my/news/ nation/2015/11/25/kemaman-prepared-to-face-flood-season/

Heisig, P. (2009). Harmonisation of knowledge management-comparing $160 \mathrm{KM}$ frameworks around the globe. Journal of Knowledge Management, 13(4), 4-31.

Kemaman flood management system, wins award in Geneva. (2016, October 23). New Straits Times. Retrieved from http://www.nst.com.my/ news/2016/10/182699/kemaman-flood-management-system-winsaward-geneva

Kemaman suffers worst flood in 50 years. (2013, December 30). Daily Express. Retrieved from http://www.dailyexpress.com.my/news. cfm?NewsID $=87684$

Mohd Rodzi, M. R., Zakaria, N. H. \& Ahmad, M. N. (2016). Ontology based knowledge integration framework for managing flood in Malaysia. Journal of Advanced Management Science, 4(6), 475-478.

Mohd Rodzi, M. R., Zakaria, N. H., Ahmad, M. N. \& Yahya, H. (2014). Towards a knowledge management framework for disaster management in Malaysia. IOS Press, 417-431.

One dead, two missing as flood situation worsens. (2013, December 6). The Star. Retrieved from http://www.thestar.com.my/news/ nation/2013/12/06/one-dead-two-missing-as-flood-situationworsens-kemaman-like-an-island-after-being-cut-off-in-all-d/

Othman, M., Ahmad, M. N., Suliman, A., \& Arshad, N. H. (2013). Towards COBIT-based framework to govern flood management. Proceeding of PACIS 2013 Conference, Paper 118, Jeju Island, Korea. 
Seneviratne, K., Baldry, D. \& Pathirage, C. (2010). Disaster knowledge factors in managing disasters successfully. International Journal of Strategic Property Management, 14(4), 376-390.

Terengganu government takes measures to alleviate flooding. (2016, December 26). The Sundaily. Retrieved from http://www.thesundaily. my/news/2107243 